\title{
Spatial and Seasonal Dynamics of Total Suspended Sediment, Total Dissolved Solids and Turbidity of a Lacustrine Reservoir in the Magoye Catchment, Southern Zambia
}

\author{
Manoah Muchanga and Henry M. Sichingabula
}

\section{ABSTRACT}

Dissolved and suspended sediment that form part of the Total Sediment Load (TSL) affects the quality of water making it unsuitable for selected aquatic invertebrates and livestock. The study aimed at determining spatial and seasonal dynamics in the concentration levels and distribution of selected physical parameters in a small lacustrine system whose main problem was punctuated by rapid deposition of clastic and none-clastic sediment. Water sampling was done during the rainy and cool-dry seasons across the reservoir using sampling bottles and DGPS. Laboratory analysis was done to determine variations in concentration levels of the parameters over time and space. Distributions of selected parameters across the reservoir were analysed using 3D Spatial Analysts Tool, Inverse Distance Weighted (IDW) in ArcGIS 10.2. Using paired T-Test at 0.05 level of significance, the study found statistically significant differences $(p<0.001)$ in the concentration of TDS, TSS, and turbidity between the rainy season and cool-dry season. With exception of TDS, TSS and turbidity were higher in the rainy season than in the cool-dry season. Rainfall was the main control variable regarding seasonality influence on TDS, TSS, and turbidity. The study concluded that although lacustrine reservoirs may be closed systems, they still experience variations spatially and temporally in terms of concentration of TDS, TSS and turbidity. The study recommends implementation of integrated catchment-wide management of anthropogenic activities so as to minimize excess generation, transportation and deposition of sediment, which punctuate elevated levels of TDS, TSS and turbidity.

Keywords: Invertebral biodiversity, Lacustrine Reservoir, Livestock, SDG14, Total Dissolved Solids, Total Suspended Sediment, Turbidity, Water Quality.

Published Online: December 22, 2021

ISSN: $2684-446 \mathrm{X}$

DOI : 10.24018 /ejgeo.2021.2.6.227

Manoah Muchanga*

Geography and Environmental Education

Section, University of Zambia, Zambia.

(e-mail: mmuchanga@unza.zm)

Henry M. Sichingabula

Geography and Environmental Studies, University of Zambia, Zambia.

*Corresponding Author

\section{INTRODUCTION}

Although sedimentation may be a natural process, in many places worldwide, it is enhanced by anthropogenic activities such as deforestation, mismanagement of riparian areas and poor farming practices especially near lacustrine systems. Sedimentation is recognized as a problem in Zambia accelerated by long history of sedentary agriculture and the large herds of cattle kept by local people especially in southern Zambia. Neglect of catchments usually punctuates reservoirs' sedimentation due to high levels of erosion, transportation, and deposition [1]. Chemical effluents and metals that are usually part of the Total Sediment Load (TSL) affect the quality of water, especially in highly managed catchments. The most obvious visual effect is that of increasing turbidity. This often affects light penetration resulting in extensive loss of lacustrine reservoir productivity [1]. Sediment may be contaminated with excessive levels of nutrients from urban and agricultural landuse [2]. Studies on water quality are broadly documented especially from outside Zambia and Africa in general [3]-[5]. Physical parameters such as TSS release heavy metal pollutants such as Lead and Cadmium, pesticides, and nutrients such as phosphorus into lacustrine systems. Others release cholera-causing bacteria, which may render water unsuitable for aquatic microphytes and livestock [6], [7]. The opacity punctuated by TSS affect the ability of aquatic organisms to catch food due to reduced transparence and visibility. Sometimes TSS and turbidity clog fish gills and decrease their resistance to diseases as well as ability to recolonize. Excess TSS may also settle in rocky habitats thus, taking up the spaces for laying of eggs and eventually, productivity [7]. Although it is generally believed that physical characteristics of water in a lacustrine system are generally uniform, this study suggests that such a perspective is not concrete universal considering the variations, which were spatial-temporally observed in the study. Generally, the study aimed at understanding the 
spatial-temporal dynamics of total suspended sediment, total dissolved solids, and turbidity of a lacustrine reservoir in the Magoye River Catchment. The study hypothesized that the concentration of TDS, TSS and turbidity significantly differed from one season to the other at $95 \%$ level of confidence.

\section{MATERIALS AND METHODS}

The targeted study area is found in the Magoye Catchment in Njola area, east of Monze Town in southern Zambia. It is specifically located between $16^{\circ} 14^{\prime} 08.4^{\prime \prime}$ South to $16^{\circ} 15^{\prime} 06.8^{\prime \prime}$ South and $27^{\circ} 40^{\prime} 52.8^{\prime \prime}$ East to $27^{\circ} 42^{\prime} 49.8^{\prime \prime}$ East with surface area of about $76,437.11 \mathrm{~m}^{2}$ (Fig. 1). It has been in existence since 1940 and, so far, is the oldest anthropogenic lacustrine system in the Magoye Catchment and whose subbasin areal extent is $5 \mathrm{~km}^{2}$ [8]. It is agroecologically located in Zone-IIa with a mean annual rainfall of $\leq 815 \mathrm{~mm}$ and a maximum temperature range of 33 to $36^{\circ} \mathrm{C}$ [9]. Geologically, it is underlain by the Zambezian belt and pedologically by, lithosols, chromic-luvisols, vertisols, orthic feralsol and nitosols [10]. Southern miombo is common [11] and, pastoral farming is a common anthropogenic activity [12]. The population of households in the catchment is over 474 of which, $77 \%$ are dependent on pastoral and crop farming [12]. By 2016, there were over 10,000 heads of cattle that depended on the lacustrine system under consideration [13].

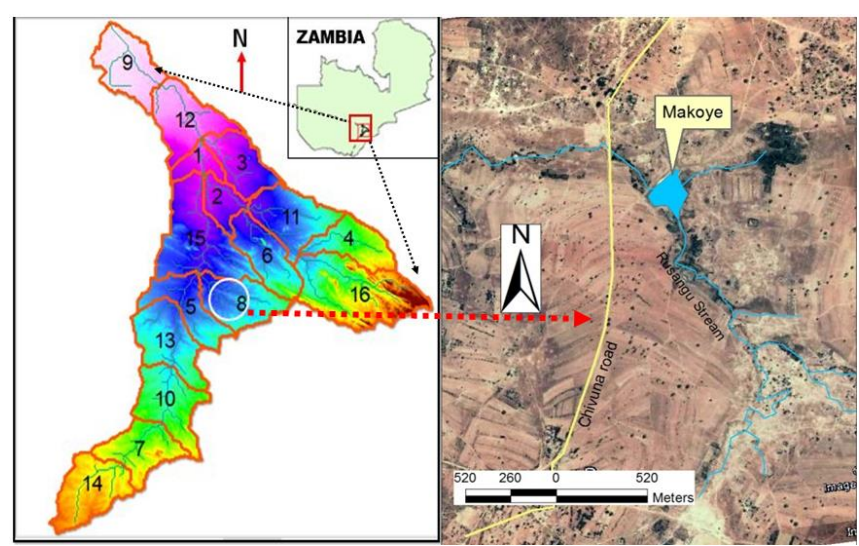

Fig. 1. General location of the study area in the Magoye Catchment.

\section{A. Sampling Process}

In order to sample the Lacustrine Reservoir, various types of snowball sampling techniques were used, namely, Exponential Non-Discriminative Snowball Sampling (ENDSS) and Exponential Discriminative Snowball Sampling (EDSS) [14]. During a reconnaissance survey, a listing of 96 reservoirs was generated using ENDSS. EDSS was used to separate 10 small lacustrine reservoirs of medium size, useful to the host communities and, which were suitable for rainy season camping. The 10 reservoirs became the final target population from which Makoye Lacustrine System was selected using Simple Random Sampling Technique (SRST) [15]. Fig. 2 summarizes the sampling process used.

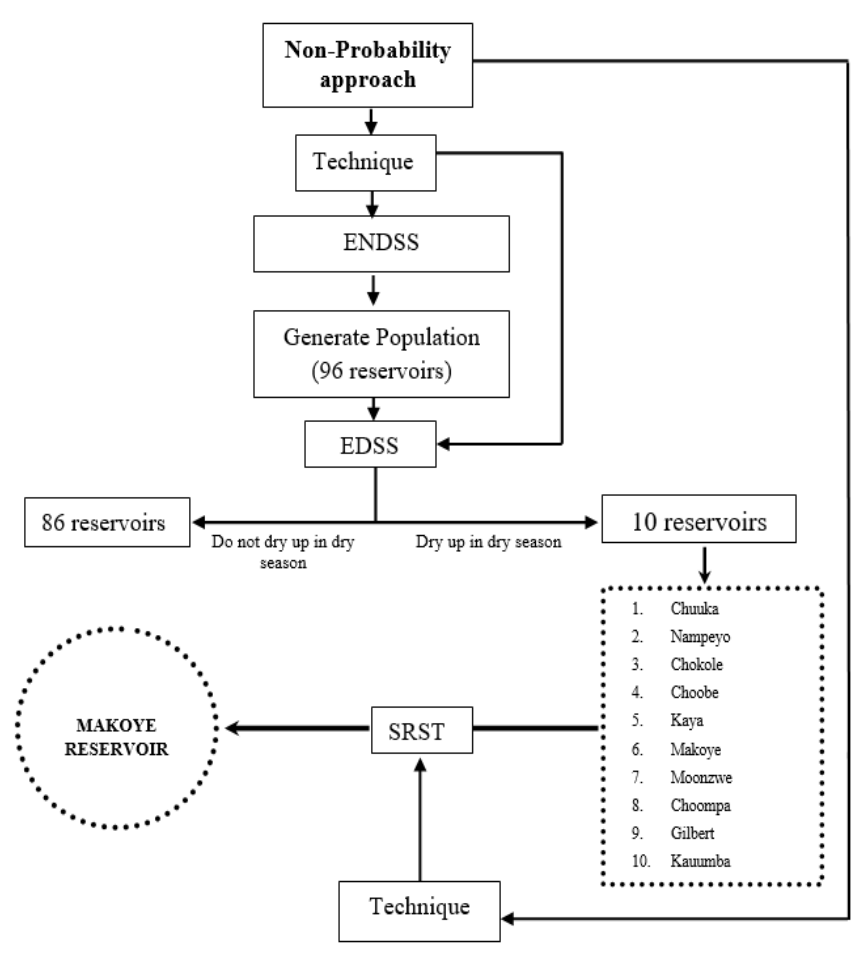

Fig. 2. Sampling framework applied in the study.

\section{B. Data Collection Process}

The research team comprising the principal investigator and two research assistants camped on the site for the whole 2015/2016 rainy season, November 2015 to March 2016. The team identified transects and points across the reservoir surface from where water samples were collected. Water was sampled across the reservoir on 3 March 2016 when the reservoir was at bankful, but before it spilled over. Samples were collected at 10 different points with the aid of an inflatable boat, Differential Global Positioning System (DGPS), and a note pad for taking coordinates. In all instances of water sampling, all bottles of water samples were clearly labelled in order to avoid mixing them up prior to laboratory analysis.

\section{Data Analysis}

To determine concentration levels of selected physical and chemical parameters, laboratory analysis was done, thereafter, results were summarised using tabular matrices [15]. Standard deviations and means with the aid of Excel Spreadsheet were also used to determine variations in concentrations of TDS, TSS and turbidity from each other and from the Maximum Permissible Limits for livestock as prescribed by FAO. In order to visualise how the concentration levels of selected physical parameters varied across the reservoir, 3-D Spatial Analysts Tool, specifically IDW Raster interpolation tool in ArcGIS 10.2 was used [16]. The input data into the GIS ArcMap interface included sampling points' coordinates in Universal Transverse Mercator (UTM), measured concentration of TDS, TSS and turbidity and wetted perimeter of the lacustrine system. 


\section{RESULTS}

Although lacustrine reservoirs are almost fully closed systems in terms of concentration of physical parameters, the study found that even such closed systems experience moderate to significant variations in the concentration of physical parameters. Total Suspended Sediment was the most variable within the target system especially during the rainy season (November-April) than during the cool-dry (May-July) season. On average $(2,805 \mathrm{mg} / \mathrm{l})$, TSS widely varied above the maximum permissible limit $(1,000 \mathrm{mg} / \mathrm{l})$ for livestock by $70 \%$, which represented a significant departure from the normal. Like TSS, turbidity was also highly variable from one point of the reservoir to the other and from one season to the other. On average, that is, 1,714.4 NTU, and it varied above the prescribed standard (1000 NTU) by $40 \%$. The average variation of Total Dissolved Sediment (TDS) was quite moderate and most stable, but intra-spatial variations were still notable from one point to the other. However, this did not imply that variations were not notable. On average, the study found TDS $(50.8 \mathrm{mg} / \mathrm{l})$ to be within acceptable concentration levels compared to permissible limits (1000 NTU) with CV of $170 \%$ (1.7). Table I shows results on concentration levels of physical parameters across the small lacustrine system.

Further evidence regarding how the concentration of TSS, TDS, and turbidity varied across the lacustrine system is presented in Fig. 3 (a-f). They all show visual impressions of unstable equilibrium in the concentration of parameters with seasonal changes in rainfall events as a major driving factor. The study found that TDS was significantly higher in the cool-dry season than in the rainy season $(\mathrm{p}<0.001)$. TSS and turbidity were very significantly higher in the rainy season than in the cool-dry season at 0.05 significance level. This suggests the significant influence of seasonal rainfall in the spatial-temporal variations of TDS, TSS and turbidity. During the rainy season, the lacustrine reservoir was still receiving surface off from rainfall, which meant high rate of sediment entry compared to the rate at which the system could homogenously mix the parameters. The turbulences due to frequent storm events in the rainy season could have also slowed sediment settling rate and possibly scoured and resuspended already settled sediment, hence increasing TSS and eventually turbidity in the rainy season. In the cool-dry season, no surface runoff enters the system, hence, most of the TSS, which predominantly influence turbidity would have already settled to the bed thereby drastically reducing TSS and turbidity. Given the lacustrine nature of the system, TSS could have had a long residence time in water (between March and July) such that, part of it further got dissolved and hence, high TDS in cool-dry season than rainy season. Generally, rainfall was the main influencing factor within the context of seasonal change.

TABLE II: SIGNIFICANCE OF THE DIFFERENCE IN CONCENTRATION OF THE PHYSICAL PARAMETERS BETWEEN RAINY AND COOL-DRY SEASONS

\begin{tabular}{cccc}
\hline Description & $\begin{array}{c}\text { T-Test } \\
\text { Results for } \\
\text { TDS }\end{array}$ & $\begin{array}{c}\text { T-Test } \\
\text { Results for } \\
\text { TSS }\end{array}$ & $\begin{array}{c}\text { T-Test } \\
\text { results for } \\
\text { Turbidity }\end{array}$ \\
\hline Paired sample & 10 & 10 & 10 \\
Df & 9 & 9 & 9 \\
t Stat & 23.75 & 11.45 & 10.47 \\
P-value & 0.0000000009 & 0.0000005 & 0.000001 \\
t Critical one-tail & 1.83 & 1.83 & 1.83 \\
Confidence Level & $95 \%$ & $95 \%$ & $95 \%$ \\
\hline
\end{tabular}

\begin{tabular}{|c|c|c|c|c|c|}
\hline Sample No & $\mathrm{X}$ & $\mathrm{Y}$ & TDS (mg/l) & TSS (mg/l) & Turbidity (NTU) \\
\hline 1 & 574803.07 & 8203961.3 & 44 & 3850 & 2252 \\
\hline 2 & 574855.45 & 8203855.4 & 56 & 2240 & 1868 \\
\hline 3 & 574736.68 & 8203846.7 & 42 & 1800 & 1174 \\
\hline 6 & 574591.94 & 8203949.4 & 42 & 2040 & 1265 \\
\hline 7 & 574695.22 & 8204061.5 & 42 & 3050 & 1807 \\
\hline 8 & 574641.14 & 8203921.7 & 40 & 2950 & 1927 \\
\hline 9 & 574750.68 & 8204137.6 & 41 & 3100 & 2130 \\
\hline 10 & 574880.2 & 8204081.8 & 68 & 2100 & 1794 \\
\hline 11 & 574823.71 & 8204131.2 & 43 & 4120 & 2254 \\
\hline 12 & 574723.08 & 8203972.9 & 90 & 2800 & 673 \\
\hline \multicolumn{3}{|c|}{ Average concentration } & 50.8 & 2805 & 1714.4 \\
\hline \multicolumn{3}{|c|}{ FAO/ OETZEL (MPL) } & 1000 & 1000 & 1000 \\
\hline \multicolumn{3}{|c|}{ Mean for Samples and MPL } & 525.4 & 1902.5 & 1357.2 \\
\hline \multicolumn{3}{|c|}{ Standard Deviation for Samples and MPL } & 671.2 & 1276.3 & 505.2 \\
\hline \multicolumn{3}{|c|}{ Coefficient of Variation, Sample mean and MPL (\%) } & 130 & 70 & 40 \\
\hline \multicolumn{3}{|c|}{ Coefficient of variation among sampling points $(\%)$} & 32 & 28 & 30 \\
\hline
\end{tabular}

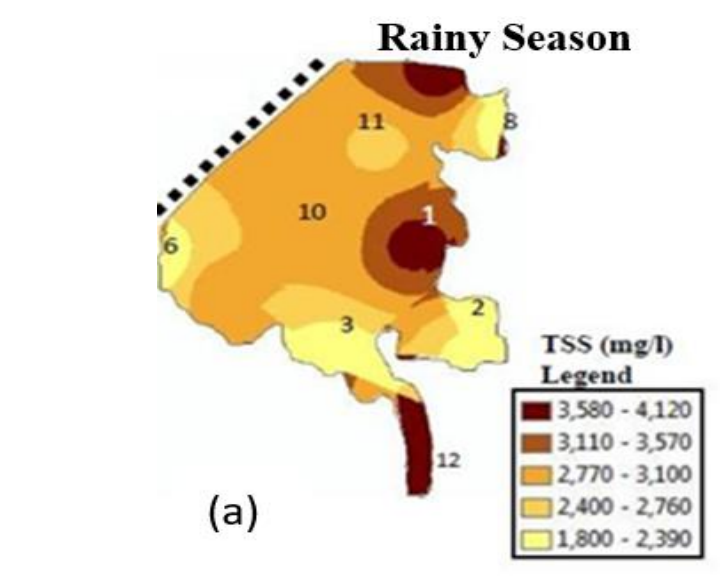

Rainy Season
............ Crest

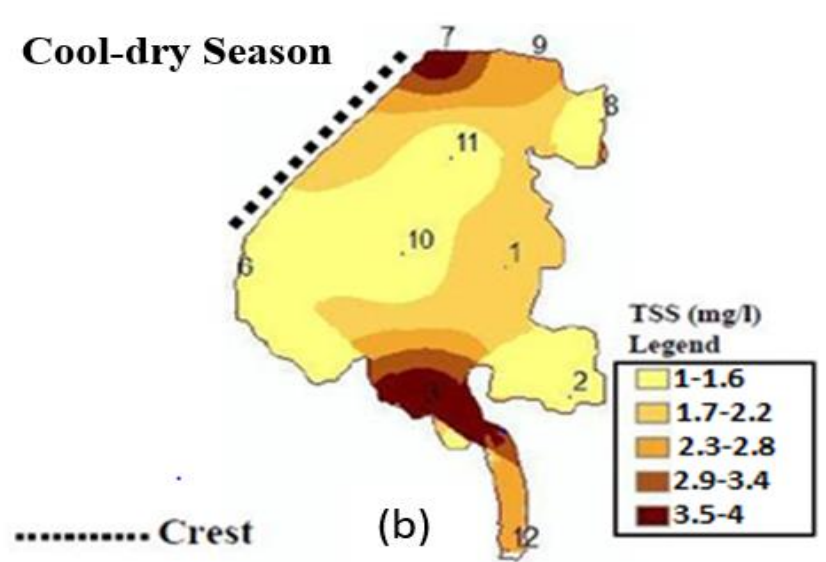



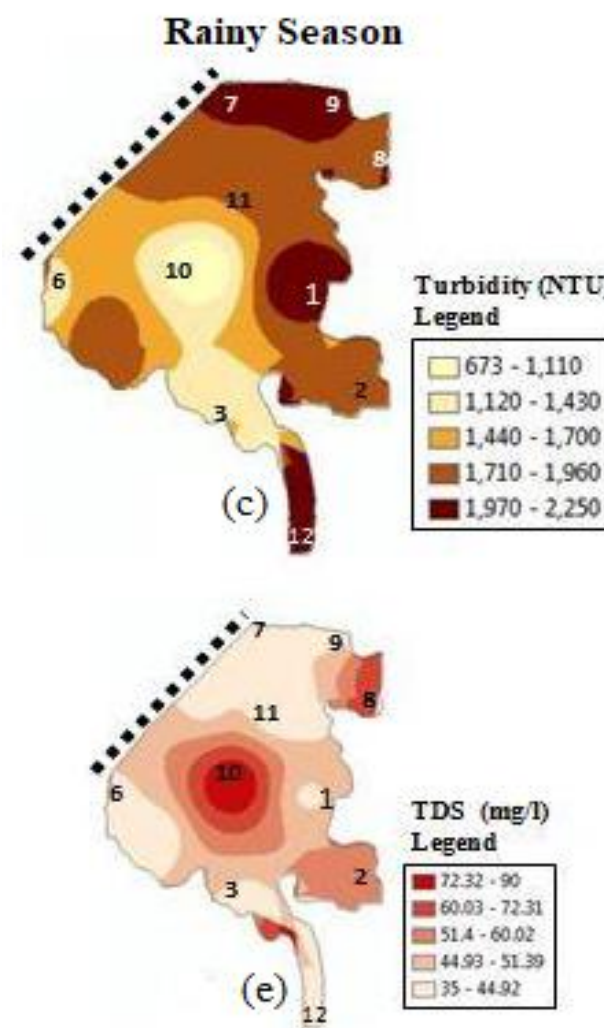

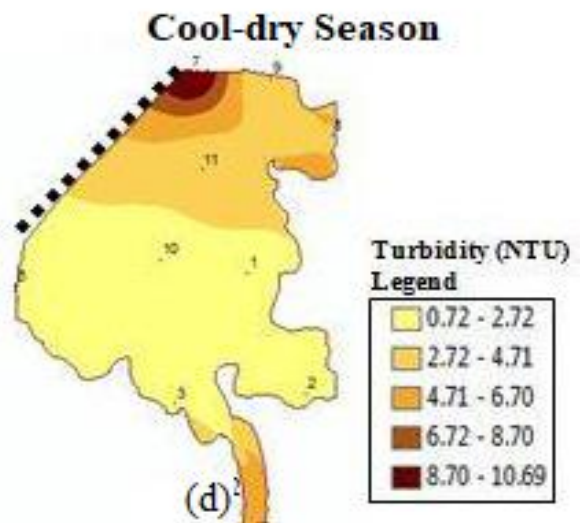

(d)

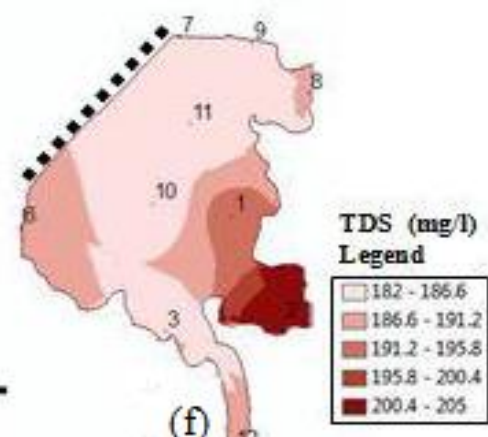

(f)

Fig. 3. Spatial-seasonal variations in the concentration of TSS during (a) Rainy Season (3/3/2016) and (b) cool-dry season (17/7/2017), Turbidity (c-d), and TDS (e-f) during Rainy Season (3/3/2016) and cool-dry season (17/7/2017).

\section{DISCUSSION}

Premised on the pieces of evidence provided in the previous section, the study argues that, although lacustrine reservoirs are generally closed systems, they experience variations in the concentration of TDS, TSS, and Turbidity. On average, the TDS was within MPL for livestock watering, wide spatial variations in its concentrations were noted and could be attributed to divergence in the character and solubility of mineral sediment deposited in the lacustrine reservoir. A similar scenario was earlier noted in another study although it was focusing on mobile hydrological systems [17]. The current findings further suggest that seasonal changes in terms of rainfall during wet season and lack of rainfall in the cool-dry season have a significant influence on the variations in concentration of TDS in non-perennial lacustrine water bodies with the lowest concentration likely to be recorded at the peak of rainy seasons and highest during the cool-dry seasons. The long residence time of sediment in the lacustrine system meant long exposure of sediment particles to water molecules and hence, a high dissolving rate resulting in high TDS in cool-dry season. Further spatial-temporal analysis revealed that none-perennial lacustrine reservoirs in the tropical region are likely to have a highly variable concentration of TDS with the highest concentrations near the bottom-set during the rainy seasons and conversely in the top-set zone during the cool-dry season. Based on the adopted methodological guideline [18], at 0.05 level of significance, TDS was significantly higher and more stable in the cool-dry season than during the rainy season $(\mathrm{p}<0.001)$. This could be attributed to the large influx of water into the reservoir in the rainy season than during the cool-dry season. The concentration levels of TDS (significantly below $1000 \mathrm{mg} / \mathrm{l}$ ) were not just favorable for livestock watering, but also suitable for optimum distribution and abundance of aquatic invertebrates that are adaptive to aquatic environments with low TDS [19].

On average, TSS was found to be significantly high in the rainy season as demonstrated by its wide departure from the MPL. Unlike TDS, TSS tended to be higher around the boundaries of the lacustrine system irrespective of the season. This could be attributed to little volumes of water that are found within this zone and rapid deposition of sediment from agricultural fields [20]. The other possible explanation for higher concentrations of TSS around the boundaries could be attributed to livestock that loosened the bank soils as they drank water around the bank such that loosened sediment found itself into the water body [21]. Moreover, as livestock especially cattle reach out for clean water towards the centre of the water body, they scour the bed and agitate the settled sediment and resuspend it into these shallow zones, hence, the high concentration of TSS. At all seasons, TSS was highly variable, but the highest magnitude of variability was observed during the rainy season. This points to large scale influx of sediment with different gravities and whose settling rates could have been influenced by variations in the volumes of water at different points of the lacustrine reservoirs and hence, the drastic changes in the levels of concentration. As of the third day of March 2016 when sampling was done, the rainfall was at its peak such that the level of water (1.29-1.89 m) [20] in the incoming stream was on the rising limb of the hydrograph, during which mobilisation and replenishment of sediment into the channel and eventually the reservoir take place [3] The exact opposite was the case during the cool-dry season 
as the streams and lacustrine reservoir's water levels $(1.04 \mathrm{~m})$ [20] were already on the falling limb of the hydrograph with little or no cascades of new allochthonous sediment. At $95 \%$ level of confidence, the study found statistically significant elevated levels of TSS in rainy season than in the cool-dry season. This suggests a very slow settling rates sediment particles compared to its influx rate in rainy season and vice versa for the cool-dry season. Sediment particle size analysis across the reservoir actually revealed the sediment particle size of $0.02 \mathrm{~mm}$ across the reservoir bed and within $50 \mathrm{~cm}$ vertical profile [8]. The elevated levels of TSS in the rainy season also points to a highly managed and eroded subbasin of the lacustrine system under consideration. Since lacustrine systems are almost perfectly closed [17], [21], the mixing process of TSS tends to be slow and hence, the spasmodic changes in the observed concentration of TSS. The finding implies that water in such lacustrine systems as Makoye may not be very safe for animal watering during rainy seasons because of elevated levels of TSS.

Although TSS and turbidity are almost always inextricably linked with high turbidity suggesting high TSS [21], this study observed a converse scenario at one of the sampling points during the rainy season (refer to point 12 , Table 1). At this point near the entry point of incoming sediment, turbidity was found to be the lowest, but with elevated concentration level of TSS. This is quite unusual, but there are three possible explanations for this phenomenon, firstly, it could be attributed to sediment that easily coagulates to each other under the presence of jellylike algae plankton of cyanobacteria family, which was physically present in the lacustrine reservoir. Secondly, it could be that, at the time of sampling, the incoming sediment was clastic with little or no refined non-clastic sediment particles that could have easily changed the water opacity at the point of entry. An earlier study [22] suggests the same although its main focus was on how the two variables predict each other. Thirdly and possibly the most probable explanation could be that none-clastic and finegrained allochthonous sediment had already been washed away from the sources, transported into the lacustrine reservoir long before the medium to coarse clastic sediment, which could be the reason why the main lacustrine reservoir had higher turbidity levels than the entry point or the edge of the throwback. Unlike some studies [23]-[25] that suggest outright linearity of the relationship between turbidity and TSS, this study suggests a reconsideration of linearity given that, in some instances, turbidity may not necessarily be linearly related to TSS depending on the character of sediment and turbidites.

Turbidity was generally spatially variable in the rainy season and on average, above the MPL. The opposite scenario was the case during the cool-dry season. Further analysis showed that at 0.05 level of significance $(p<0.001)$, turbidity was significantly higher during the rainy season than during the cool-dry season. This implies that water of a lacustrine system in a highly managed catchment could be safer for livestock watering during the cool-dry season than during the rainy season because, during the cool-dry season, much of the TSS is deposited to the bed, but during the rainy season, TSS transportation is more prevalent than deposition
[21]. According to [10], surface water whose turbidity goes beyond $1000 \mathrm{NTU}$ is susceptible to chlorine-resistant pathogens such as Cryptosporidium, which cause animal diseases such as diarrhea. The Zambia Ministry of Livestock and Fisheries 2016 livestock census confirmed that some cattle in the catchment suffered from reduced immune system and diarrhea partly due to poor quality of water leading to death and reduction in the population of cattle between 2015 and 2016 [13]. Generally, the findings have implications on the biological safety of water for animals and even people alike given the unstable nature of the variables which were studied especially TSS and turbidity. Aquatic invertebral biodiversity is also under threat because of the dynamic nature of the concentration of TDS, TSS, and turbidity. If these are not frequently monitored and assessed, they are a deterrent to successful and localized implementation of SDG 14 concerning sustainable life under waters of non-perennial lacustrine systems. Hence, an understanding of geophysical processes such sediment fluxes and deposition is critical in the management of threatened lacustrine systems and generally, life underwater. Continuous assessment of the status of concentration of physical parameters in general and particularly their possible implications on livestock and aquatic biodiversity is useful in exploring new ways of increasing benefits from chemical sediment in lacustrine reservoir whilst reducing any detrimental effects. Understanding the physical characteristics of lacustrine reservoirs could be a perfect scanning tool to determine the nature of landuse across the whole catchment and may help in devising the best catchment management strategies that are community engaged and are responsive to climate action for sustainable integrated water resources management and adaptive landuse [26].

\section{CONCLUSION}

Based on the findings of the study, it can be concluded that small lacustrine reservoir with highly managed basins experiences elevated levels of TSS and Turbidity, during the rainy season than cool-dry season. Both spatial and temporal variations are common in small none-perennial lacustrine systems, which inspired the conclusion that seasonal and geospatial changes have influence on the concentration of TDS, TSS, and turbidity. Seasonal changes in terms of rainfall have a statistically significant influence on the variations in the concentration of TDS, TSS, and turbidity. Although some studies have concluded about strong linearity of the relationship between TSS and turbidity, this may not always be the case for all hydrological systems because geophysical and landuse processes vary from one space to the other. This study focused on a singular nonperennial lacustrine reservoir, notwithstanding that, the findings may well have a bearing on other lacustrine systems with homogenous characteristics as the one studied. The findings raise important theoretical issues that have a bearing on the realization of sustainable water resources management, life underwater, livestock management and aquatic invertebral biodiversity. Hence, the need for further research and implementation of sustainable catchment management practices that do not only reduce excess 
sediment production, transportation and deposition to where they are least desirable, but also ensure that communities are educated to participate in the implementation of the control measures against excess siltation for sustainable water resilience amidst the changing climate.

\section{FUNDING}

This study was undertaken under Task 109 project whose funding was received from the Southern African Science Service Centre for Climate Change and Adaptive Land Use (SASSCAL) funded by German Federal Ministry of Education and Research (BMBF) (Project Grant Number 01LG1201M), and partly from the Zambian Government.

\section{COMPETING INTERESTS}

The authors have no competing interests to declare.

\section{ACKNOWLEDGMENT}

All authors contributed equally to the study.

\section{REFERENCES}

[1] Sichingabula H.M. The Problem of Sedimentation in Small Dams in Zambia. Proceedings of the IAHS, 1997.

[2] Enhui J. Sedimentation Bears on the Life of Reservoirs. http://www.tcsr-icold.com/Detail/46 (28/4/2014), 2012.

[3] Kithiia S.M. and Mutua F.M. Impacts of land-use changes on sediment yields and Water quality within the Nairobi River subbasins, Kenya; In: Sediment Dynamics and the Hydromorphology of Fluvial Systems. Nairobi: Hyslop, 2006.

[4] Mudyazhezha S. and Kanhukamwe R. Environmental Monitoring of the Effects of Conventional and Artisanal Gold Mining on Water Quality in Ngwabalozi River, Southern Zimbabwe. International Journal of Environmental Monitoring and Analysis. 2014; 2; 123 127.

[5] Sracek B., Bohdan K., Mihaljevič M., Majer V., František V., Zbyněk V. and Nyambe I. Mining-Related Contamination of Surface Water and Sediments of the Kafue River Drainage System in the Copperbelt District, Zambia: An Example of a High Neutralization Capacity System. Journal of Geochemical Exploration. 2012; 112:174-188.

[6] Dawson EJ, Macklin MG. Speciation of heavy metals on suspended sediment under high flow conditions in the River Aire, West Yorkshire, UK, Hydrol. Process, 12, 1483 1494, 1998.

[7] Naden P., Old G., Quinton J.N., Smith B., Worsfold P.J. Processes affecting transfer of sediment and colloids, with associated phosphorus, from intensively farmed grasslands: an overview of key issues, Hydrological Process, 20, 2006.

[8] Muchanga M. Determination of Sediment and Water Quality and Quantity for SWAT Modelling of Sedimentation in the Magoye Reservoir, Southern Zambia. Lusaka: University of Zambia, 2020.

[9] Zambia Meteorological Department (ZMD). Weather and Climate Data. Lusaka: ZMD, 2014.

[10] FAO. Guidelines Sheet of Water Quality Standards for Livestock. New York: FAO, 1978.

[11] Storr, A.E.G. (ed.). Know Your Trees. Lusaka: Zambia Forest Department Publishing, 1995.

[12] Central Statistical Office (CSO). National Census of Housing and Population. Lusaka: CSO, 2010.

[13] Ministry of Livestock and Fisheries (MLF). Livestock Census Report 2015. Monze: MLF, 2016.

[14] Castillo J.J. Snowball Sampling. Experiment Resources. http://www.experiment-resources.com/snowball-sampling.html. (16/02/2016), 2009.

[15] Bryman A. Social Research Methods. New York: Oxford University, 2008.

[16] Harder C. The ArcGIS Book. California: ESRI Press, 2017.

[17] Xun Z., Hua Z., Liang Z., Ye S., Xia Y., Rui L. and Li Z. Some factors affecting TDS and $\mathrm{pH}$ values in groundwater of the Beihai coastal area in southern Guangxi, China. Environ Geol, 2007; 53:317-323 (2007). https://doi.org/10.1007/s00254-007-0647-4.

[18] de Winter J.C.F. Using the Student's t-test with extremely small sample sizes. Practical Assessment, Research \& Evaluation, 2013; 18(10). Available online: http://pareonline.net/getvn.asp?v=18\&n=10. (Accessed: 25/2/2018)

[19] Olson J.R. and Hawkins C.P. Effects of Total Dissolved Solids on Growth and Mortality Predict Distributions of Stream Macro invertebrates. Freshwater Biology, 2017; 62:779-791.

[20] Muchanga M., Sichingabula H. M., Obando J., Chomba I.C., Sikazwe H. and Chisola M. Bathymetry of the Makoye Reservoir and its Implications on Water Security within the Catchment. International Journal of Geography and Geology. 2019; 8(3):93-109.

[21] Sichingabula M. H. Clastic Sediment Flux into Indian and Pacific Oceans by Rivers in Central Southern Africa and Western Canada. Manaus99- Hydrological and Geochemical Processes in Large Scale River Basins. 2000, p. 15- 19. Manaus, Brazil.

[22] Serajuddin M., Chowdhury A.I., Haque M and Haque E. Using Turbidity to Determine Total Suspended Solids in an Urban Stream: A Case Study. 2nd International Conference on Water and Environmental Engineering 19-22 Jan 2019, Dhaka.

[23] Butler, B.A. and Ford, R.G. Evaluating relationships between total dissolved solids (TDS) and total suspended solids (TSS) in a mininginfluenced watershed. Mine Water Environ. 2018 March 31; 2019; 37(1): 18-30. Doi: 10.1007/s10230-017-0484-y.

[24] Hern T. K., Hin L. S., Ibrahim S., Sulaiman N. M. N., Sharifi M., \& Abe S. Impact of Fine Sediment on TSS and Turbidity in Retention Structure. Journal of Geoscience and Environment Protection, 2014; 2:1-8. http://dx.doi.org/10.4236/gep.2014.24001.

[25] Ziegler A.C. Issues Related to use of Turbidity Measurements as a Surrogate for Suspended Sediment. Turbidity and Other Sediment Surrogates Workshop, April 30 - May 2, 2002. http://ks.water.usgs.gov/Kansas/rtqw/ (17/3/2017).

[26] Muchanga, M. A Survey of Public Participation in Planning for Climate Change Adaptation among Selected areas of Lusaka Province. American International Journal of Contemporary Research. 2012; 2:81-90. ISSN 2162-139. www.aijcrnet.com/journals/Vol_2_No_8_August_2012/8.pdf.

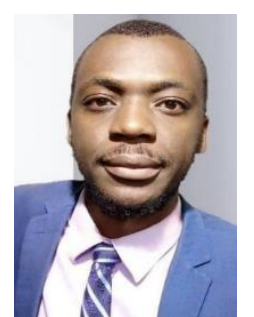

Manoah Muchanga is a Doctor of Philosophy in Fluvial Geomorphology earned from the University of Zambia School of Natural Sciences in 2020. His $\mathrm{PhD}$ was sponsored by the Southern Africa Science Service Centre for Climate change and Adaptive Land Management (SASSCAL) under Task 109. He holds a Masters Degree with emphasis on Climate Change and Learning also awarded by the University of Zambia in 2011. His meritorious bachelor's degree with Geography Major was obtained in 2008 at the same institution. Dr. Manoah Muchanga holds advanced certificates in Research Methodology from Rhodes University-South Africa, Geographical Information System \& Hydrological Modelling from DELFT IHE in the Netherlands, Project Management from WESSA-South Africa. $\mathrm{He}$ is currently a researcher and lecturer at the University of Zambia. His current research interest is in water and sediment; water education, environment and learning, climate change; social hydrology and river restoration, strategic planning, and research methodology. He is also the founder and Executive Director of Widelogic Consultancy and Training specialised in sediment and water research. 